\title{
Polyol mediated synthesis and electrochemical performance of nanostructured $\mathrm{LiMn}_{2} \mathrm{O}_{4}$ cathodes
}

 \\ ${ }^{1}$ Institute of Inorganic Chemistry, RWTH Aachen University, Landoltweg 1, 52074 Aachen, Germany \\ 2 JARA-FIT, 52056 Aachen, Germany. \\ *E-mail: ulrich.simon@ac.rwth-aachen.de
}

doi: $10.20964 / 2016.12 .96$

Received: 26 August 2016 / Accepted: 15 October 2016 / Published: 10 November 2016

\begin{abstract}
Nanoparticulate single phase $\mathrm{LiMn}_{2} \mathrm{O}_{4}$ spinel was prepared via polyol method and applied as a cathode in a lithium ion battery. The effects of calcination temperature $\left(250{ }^{\circ} \mathrm{C}-800{ }^{\circ} \mathrm{C}\right)$ as well as of postsynthetic treatment by ball milling on the physiochemical and electrochemical properties of $\mathrm{LiMn}_{2} \mathrm{O}_{4}$ were studied by means of powder XRD, SEM, cyclic voltammetry and charge/discharge cycling. With increasing calcination temperature, the electrochemical activity and discharge capacity increased. The measurements revealed that the electrochemical performance of $\mathrm{LiMn}_{2} \mathrm{O}_{4}$ can be further improved by ball milling before calcination. Furthermore, the ball milling process allowed reducing the calcination temperature needed to obtain electrochemically active material.
\end{abstract}

Keywords: Lithium ion battery, $\mathrm{LiMn}_{2} \mathrm{O}_{4}$ spinel, nanoparticles, calcination, ball milling

\section{FULL TEXT}

(C) 2016 The Authors. Published by ESG (www.electrochemsci.org). This article is an open access article distributed under the terms and conditions of the Creative Commons Attribution license (http://creativecommons.org/licenses/by/4.0/). 